\title{
Intra-atrial calcium infusions, growth, and development in end organ resistance to vitamin $\mathrm{D}$
}

\author{
J-P Lin, W S Uttley
}

\begin{abstract}
A five and a half year follow up of a girl with end organ resistant rickets is described. After failing to respond to high dose oral alfacalcidol (4 $\mu \mathrm{g} / \mathrm{kg} / \mathrm{day})$ and calcium supplements, treatment for one year with domiciliary intra-atrial calcium infusions at 2 years of age induced a complete remission, which was maintained on subsequent high dose oral calcium supplement. Overnight infusions were well tolerated without adverse cardiovascular or renal sequelae or ectopic calcification. If the first three years of life are survived, the prognosis for a normal life on oral treatment is excellent.

(Arch Dis Child 1993; 69: 689-692)
\end{abstract}

End organ resistance to 1,25 dihydroxyvitamin $\mathrm{D}_{3}\left(1,25(\mathrm{OH})_{2} \mathrm{D}_{3}\right)$ is a rare autosomal recessive disorder characterised by rickets which proves refractory to conventional vitamin $\mathrm{D}$ replacement. Cases have been reported from North America, North Africa, and the Middle East and it may be fatal if untreated in the first three years of life. ${ }^{1}$ DNA sequencing of the vitamin $D$ receptor was established in $1988^{2}$ and the defect was shown to arise from point mutations of the 'zinc fingers' of the DNA binding domain of the vitamin $\mathrm{D}$ receptor later that year. ${ }^{3}$ Long term remission from rickets can be safely induced with an initial course of regular calcium infusions followed by oral treatment.

\section{Case report}

A girl with end organ resistance to 1,25 $(\mathrm{OH})_{2} \mathrm{D}_{3}$ born in the UK to fourth generation Indian, non-consanguinous parents originating from Mauritius, has been followed up from the age of 4 months to 6 years. At 4 months of age she sustained a supracondylar fracture of the right femur and a retrospectively assessed skeletal survey demonstrated rickets. At 1.3 years she was referred to us with delayed motor milestones and was unable to weight bear. There was clinical, radiological, and biochemical evidence of severe rickets. Symptoms included irritability, apparent bone pain, anorexia, failure to thrive, weakness, motor and speech delay. Alopecia was striking (fig 1). Biochemical changes included hypocalcaemia, hypophosphataemia, secondary hyperparathyroidism, a raised alkaline phosphatase in excess of $10000 \mathrm{IU} / 1$ and aminoaciduria. A jejunal biopsy specimen, sweat test, and renal function measurement gave normal results. Two

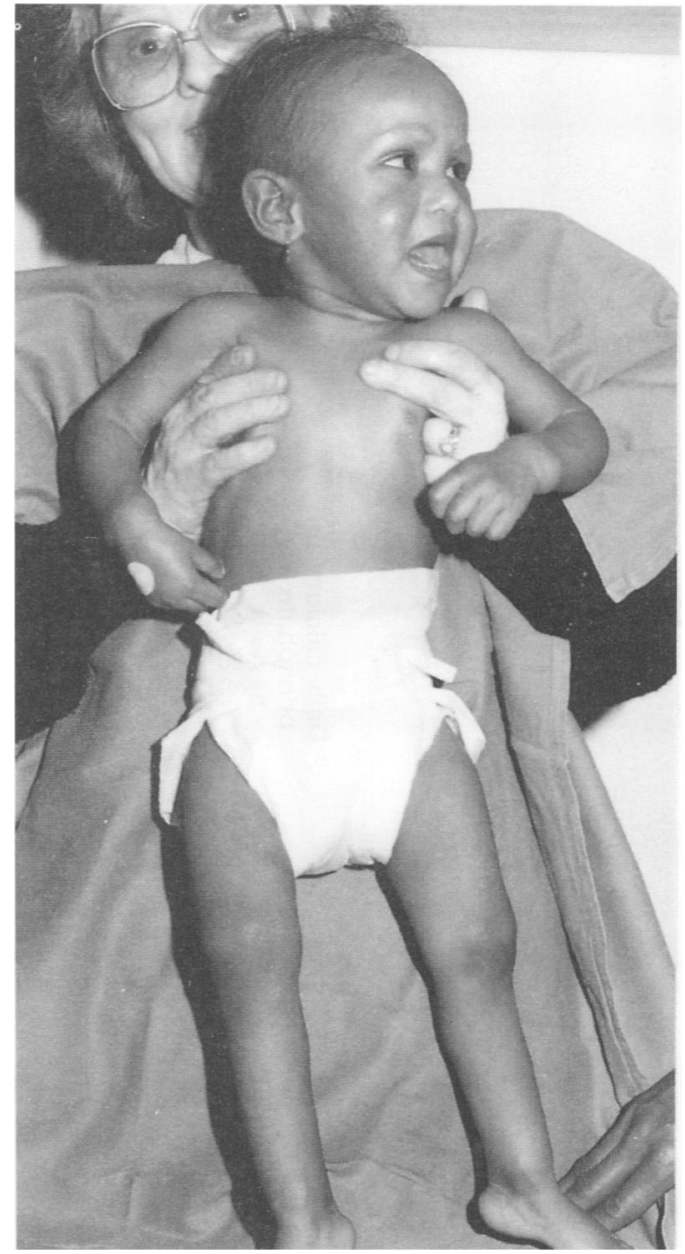

Figure 1 Clinical features before calcium infusions. Patient aged $2 \cdot 2$ years before intra-atrial calcium infusions. Note alopecia, metaphyseal flaring at wrist and ankle, and inability to bear weight.

intramuscular injections of $300000 \mathrm{IU}$ of cholecalciferol $\left(25(\mathrm{OH}) \mathrm{D}_{3}\right)$ at 1.3 and 1.4 years of age and daily oral alfcalcidol $\left(1 \alpha(\mathrm{OH}) \mathrm{D}_{3}\right)$ between 1.4 and $2 \cdot 2$ years up to a maximum of $30 \mu \mathrm{g} /$ day, equivalent to 4 $\mu \mathrm{g} / \mathrm{kg} /$ day, failed to induce a clinical response though the plasma $1,25(\mathrm{OH})_{2} \mathrm{D}_{3}$ concentration was excessively raised at $400 \mathrm{pg} / \mathrm{ml}$ (normal range $30-50 \mathrm{pg} / \mathrm{ml}$ ). Complete end organ resistance to $1,25(\mathrm{OH})_{2} \mathrm{D}_{3}$ was subsequently confirmed on skin fibroblast cultures (A $\mathrm{R}$ Rut et al, personal communication). Normal receptor binding of $1,25(\mathrm{OH})_{2} \mathrm{D}_{3}$ was shown but there was no in vitro conversion of $25(\mathrm{OH}) \mathrm{D}_{3}$ to $24,25(\mathrm{OH})_{2} \mathrm{D}_{3}$.

INTRA-ATRIAL CALCIUM INFUSION REGIMEN Intra-atrial infusions of calcium glubionate (calcium gluconogalactogluconate, Sandoz
Correspondence to: Dr Uttley.

Accepted 3 August 1993
Royal Hospital for Sick Road, Edinburgh EH9 1LF J-P Lin 
Laboratories, Basle, Switzerland) were administered via a subcutaneous Port-a-Cath central venous access device with the catheter tip in the right atrium. Infusions began at an initial dose of $200 \mathrm{mg} /$ day of the calcium salt made up to a volume of $500 \mathrm{ml}$ with a solution of $5 \%$ dextrose, rising to $400 \mathrm{mg} / 500 \mathrm{ml} /$ day on day 3 , increasing to $500 \mathrm{mg} /$ day from day 7 with nocturnal infusions from day 14 . The parents learned the technique of aseptic infusions using a programmable pump and were supported by the nursing home care team.
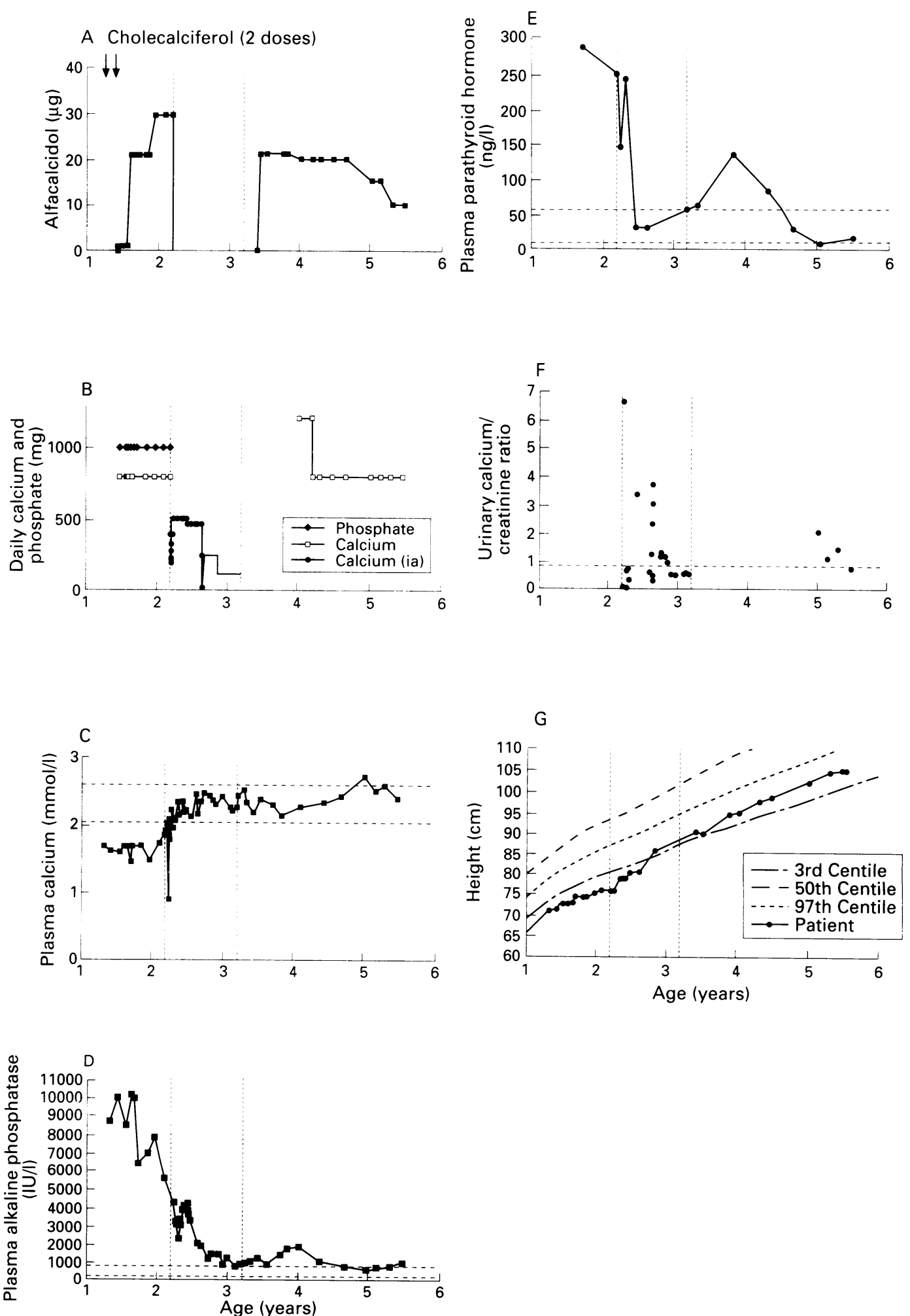

Figure 2 Biochemical profile and growth against age before, during, and after calcium infusions. The period of calcium infusions is contained between the vertical dotted lines for all graphs. Normal ranges are indicated by the dashed horizontal lines. (A) Daily oral alfacalcidol ( $\mu g$ ) and two intramuscular injections of cholecalciferol (300 000 IU) (B) Daily oral calcium and phosphate effervescent salts ( $\mathrm{mg}$ ) and daily intra-atrial (ia) calcium infusion dose (mg). (C) Plasma calcium (mmoll). (D) Plasma alkaline phosphatase. (E) Plasma immune parathyroid hormone (ng/). (F) Urinary calcium/ creatinine ratio. (G) Patient height $(\mathrm{cm})$. Note there were no episodes of hypercalcaemia during calcium infusions, but hypercalcaemia with oral calcium and alfacalcidol at the age of $5(C)$. The parathyroid hormone fell to normal after three months of intra-arterial calcium infusions (E) but the alkaline phosphatase was slower to respond (D). The intra-atrial and oral doses of calcium are titrated to the interinfusion calcium/creatinine ratios $(B, F)$. Growth crosses the $3 r d$ centile during the calcium infusions, progressing to the 25th centile $(G)$. 
Calcium glubionate:5\% dextrose solutions were prepared by the hospital pharmacy weekly. Plasma concentrations of calcium, phosphate, urea, electrolytes, and creatinine, urinary calcium/creatinine ratios, and alkaline phosphatase activities were obtained by weekly and then monthly checks, as was height. Apart from one episode of the Port-a-Cath clotting soon after the start of the infusions, the system remained trouble free.

\section{CLINICAL AND BIOCHEMICAL COURSE DURING} CALCIUM INFUSIONS

Figure 1 illustrates the clinical picture before calcium infusions at $2 \cdot 2$ years. Figure 2 (A-G) plots the biochemical course and height before, during, and after the year of intra-atrial
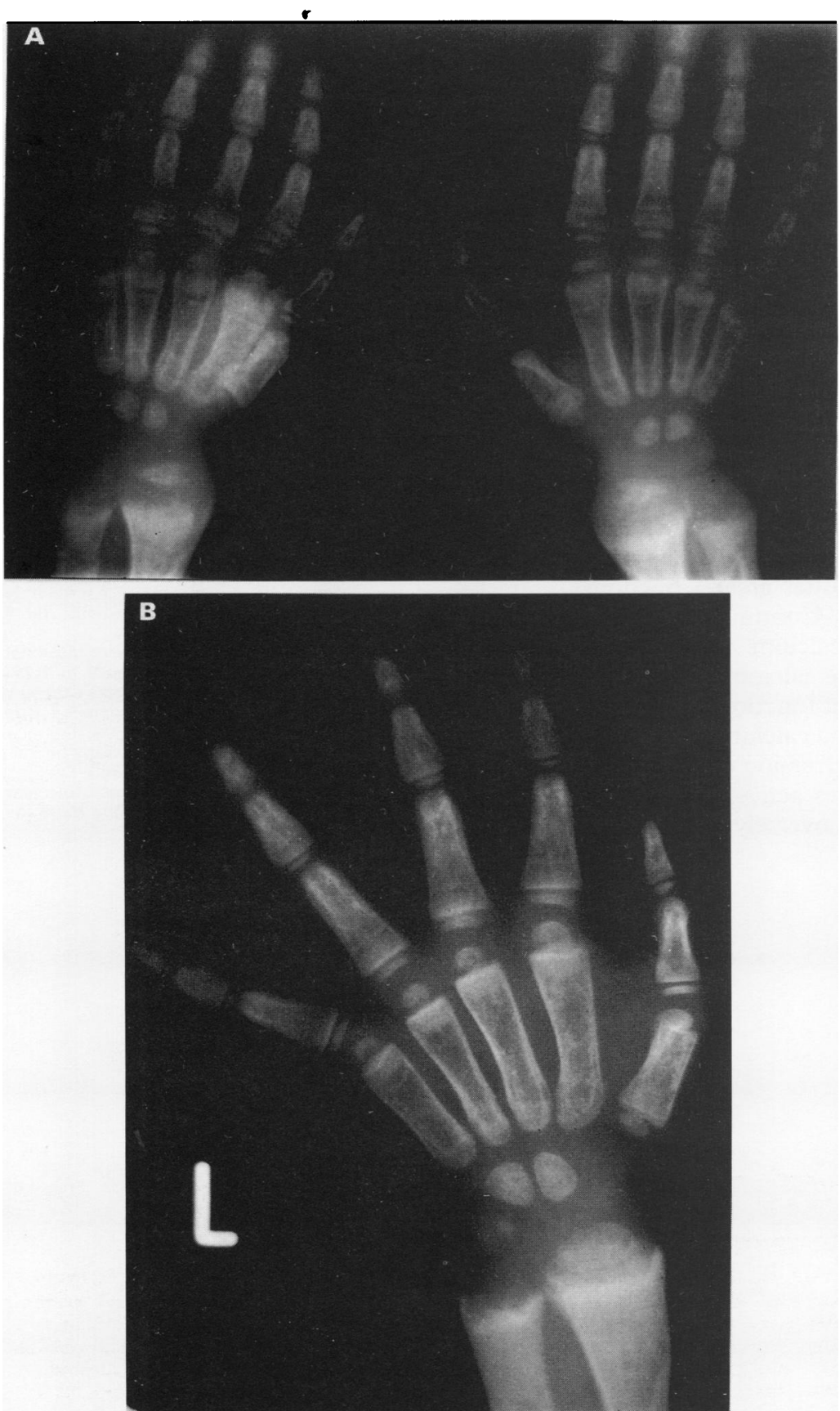

Figure 3 Effect of intra-atrial calcium infusions on bone mineralisation. (A) Both hands before calcium infusions. (B) Ten weeks after the start of infusions, bone healing is evident, with reduction in soft tissue swelling. calcium infusions, indicated by the vertical dotted lines for all graphs. The infusions were well tolerated with no episodes of hypercalcaemia or electrolyte disturbance. Irritability was abolished and appetite restored within 24 hours of the start of the infusions. Attention, concentration, and language improved rapidly. Standing and walking with support began one week after starting infusions, and walking unsupported after four months of treatment at 2.5 years of age. Height achieved the 3 rd centile for age after eight months (fig $2 \mathrm{G}$ ). No cardiac arrhythmias or neurological sequelae were detected during the first two weeks of monitored infusions or subsequently. Renal function remained normal throughout and there was no evidence of nephrocalcinosis or ectopic calcification. Plasma concentrations of calcium and phosphate fluctuated at the lower limit of normal $(2.1$ and $1.0 \mathrm{mmol} / 1 \mathrm{respec}-$ tively) for the first month of infusions (fig $2 \mathrm{C}$ ). The plasma immune parathyroid hormone concentration became normal after 12 weeks (fig 2E), falling from $249 \mathrm{ng} / 1$ to $31 \mathrm{ng} / \mathrm{l}$ (normal range $10-55 \mathrm{ng} / \mathrm{l}$ ). Bone healing was complete by five months, though radiological change began 10 weeks after starting infusions (fig $3 \mathrm{~A}, \mathrm{~B}$ ), accompanied by a fall in alkaline phosphatase from $4325 \mathrm{IU} / 1$ to the upper limit of normal (fig 2D) and resolution of the aminoaciduria. Calcium infusions were titrated down to $120 \mathrm{mg} / 500 \mathrm{ml} / 12$ hours against interinfusion urinary calcium/creatinine ratios (fig $2 \mathrm{~A}, \mathrm{~F}$ ).

\section{COURSE AFTER INFUSION}

Infection of the skin overlying the Port-a-Cath after one year required removal of the access device under antibiotic cover. Owing to a progressive rise in the parathyroid hormone and alkaline phosphatase after stopping calcium infusions (fig 2E, D), oral alfacalcidol, up to 20 $\mu \mathrm{g} / \mathrm{day}$, was restarted. This failed to prevent further rises, which only responded to the reintroduction of $1200 \mathrm{mg} /$ day of oral calcium salt. At the age of 5, on $10 \mu \mathrm{g}$ of alfacalcidol and $800 \mathrm{mg}$ of oral calcium daily, the cal- cium/creatinine ratio (fig $2 \mathrm{~F}$ ) rose to 2.5 (normal $<1$ ), requiring further reductions in oral supplements (fig $2 \mathrm{~A}, \mathrm{~B}$ ). Growth continued along the 25th centile for height and there were no clinical symptoms of rickets.

\section{Discussion}

Reports of sporadic and multiple cases of 1,25 $(\mathrm{OH})_{2} \mathrm{D}_{3}$ resistant rickets since the original description by Brooks in 1978 in a black American woman, ${ }^{4}$ have included North African $^{5}$ or Middle Eastern ${ }^{6}$ families of Arabic descent in whom consanguinity is often, but not exclusively, a feature. The defect is characterised in our case by a point mutation in the amino acid sequence in the zinc finger region of the vitamin D receptor (A R Rut et al, personal communication) which normally binds to the nuclear DNA of the target cell for enzyme induction. There is normal 1,25 $(\mathrm{OH})_{2} \mathrm{D}_{3}$ hormone to receptor binding. The 
principal role of $1,25(\mathrm{OH})_{2} \mathrm{D}_{3}$ is the active transport of calcium from the gut, though vitamin D receptors have been found in most tissues. ${ }^{7}$ However, parenteral calcium alone may be sufficient for bone mineralisation. ${ }^{8}$ Fatal respiratory infections have been reported if the rickets is not brought under control under the age of 3 years. ${ }^{1}$

As the graphs of the clinical and biochemical course of our case illustrate, long term calcium infusions appeared necessary to induce a remission from total body calcium depletion, which became clinically and radiologically gross by the age of 4 months due to exhaustion of placentally acquired calcium stores. Our data suggest that oral calcium supplements appeared to induce a slow biochemical change, which may have been independent of a high dose alfcalcidol intake of up to $30 \mu \mathrm{g} /$ day before calcium infusions. This was not matched by clinical or radiological improvement. Intra-atrial calcium infusions resulted in a rapid clinical, radiological, and biochemical recovery similar to short term results that had been reported in three previous case series involving four patients 569 by the time we began infusions in March 1989. Unlike a recently published report of long term follow up in 10 cases spanning two kindreds, ${ }^{10}$ biochemical resolution in our case was complete after three months of infusions.

We did not have problems of hypercalcaemia and bradycardia as described by Hochberg et al. ${ }^{10}$ In contrast to the mean septicaemia onset time of eight months in the Hochberg series, our patient never became septicaemic but developed an infection around the Port-a-Cath after one year of needle punctures. A subcutaneous implant may protect against sepsis as well as offer greater freedom for normal activities. Continued clinical improvement on oral calcium supplements remains intriguing as little calcium is absorbed enterally in the absence of functioning vitamin $D$ receptors. ${ }^{11}$ Low plasma calcium concentrations normally induce conversion of 25 to 1,25 $(\mathrm{OH})_{2} \mathrm{D}_{3}$ which stimulates active transport of calcium from the gut. Conversely, enteral cal- cium absorption is down regulated via the concentration of $1,25(\mathrm{OH})_{2} \mathrm{D}_{3}$. Once bones are calcium replete, high dose oral calcium maintains remission.

\section{CONCLUSION}

Monotherapy with domiciliary calcium infusions for one year induced a striking remission of severe rickets in a 2 year old girl who had proved refractory to initial oral treatment. Infusions with appropriate outpatient and home care nursing back-up, proved practical and safe. A urinary calcium/creatinine ratio of $>1$ between infusions indicates the need to reduce the daily calcium intake, and a normal parathyroid hormone is the best guide to continued remission, whether calcium is administered parenterally or orally.

Special thanks to the RHSC Nursing Home Care Service, the pharmacy and biochemistry department. We are grateful to pharmacy and biochemistry department. We are grateful to this work was delivered to the Scottish Paediatric Society.
the

1 Fraher LJ, Karmali R, Hinde FRJ, et al. Vitamin D-dependent rickets type II: extreme end organ resistance to 1,25 dihydroxy vitamin D 3 in a patient without alopecia. Eur $\mathcal{F}$ dihydroxy vitamin D3 in a

2 Baker AR, McDonnell DP, Hughes $M$, et al. Cloning and expression of full-length cDNA encoding human vitamin D receptor. Proc Natl Acad Sci USA 1988; 85: 3294-8.

3 Hughes MR, Malloy PJ, Kieback DG, et al. Point mutation in the human vitamin $D$ receptor gene associated with hypocalcaemic rickets. Science 1988; 242: 1702-5.

4 Brooks MH, Bell NH, Love L, et al. Vitamin D-dependent rickets type II. Resistance of target organs to 1,25 , dihydroxy-vitamin D. N Engl f Med 1978; 298: 996-9. turnal calcium infusions can cure rickets and promote turnal calcium infusions can cure rickets and promote nor

6 Weisman Y, Bab I, Gazit D, Spirer Z, Jaffe M, Hochberg Z. Long-term intracaval calcium infusion therapy in endorgan resistance to 1,25-dihydroxyvitamin D. Am $\mathcal{F} \mathrm{Med}$ 1987; 83: 984-90.

7 Reichel H, Koeffler P, Norman AW. The role of the D endocrine system in health and disease. $N$ Engl $\mathfrak{f} M e d$ 1989; 320: 980-91.

8 Underwood JL, DeLuca HF. Vitamin D is not directly necessary for bone growth and mineralisation. $\mathrm{Am} \mathcal{F}$ Physiol 1984; 246: E493-8.

9 Bliziotes M, Yegey AL Nanes MS, et al. Absent intestina response to calciferols in hereditary resistance to $1,25-$ response to calciferols in hereditary resistance to 1,25dihydroxyvitamin D: documentation and effective therapy with high dose intravenous calcium

10 Hochberg Z, Tiosano D, Even L. Calcium therapy for calcitriol-resistant rickets. $\mathcal{F}$ Pediatr 1992; 121: 803-7.

11 Haussler MR, Mangelsdorf DJ, Komm BS, et al. Molecular biology of the vitamin D hormone. Recent Prog Horm Res 1988; 44: 263-97. 